AUTHOR CORRECTION OPEN

\title{
Author Correction: Mimicking immune signatures of flavivirus infection with targeted adjuvants improves dengue subunit vaccine immunogenicity
}

Katell Bidet ${ }^{1}$, Victor $\mathrm{Ho}^{2,3}$, Collins Wenhan $\mathrm{Chu}^{4}$, Ahmad Nazri Mohamed Naim ${ }^{4}$, Khaing Thazin ${ }^{5}$, Kuan Rong Chan (iD ${ }^{6}$, Jenny G. H. Low $\mathbb{D}^{6,7}{ }^{6,}$ Milly M. Choy ${ }^{4}$, Lan Hiong Wong ${ }^{1}$, Paola Florez de Sessions ${ }^{4}$, Yie Hou Lee ${ }^{8}{ }^{8}$, Martin L. Hibberd ${ }^{9}$, Eng Eong Ooi ${ }^{1,6}$, Katja Fink (iD) ${ }^{2,3}$ and Jianzhu Chen ${ }^{1,10 *}$

npj Vaccines (2019)4:46

; https://doi.org/10.1038/s41541-019-0140-6

Correction to: npj Vaccines https://doi.org/10.1038/s41541-0190119-3, published online 25 June 2019

The original version of this Article contained an error in the spelling of the author Ahmad Nazri Mohamed Naim, which was incorrectly given as Ahmad Nazri Hohamed Naim. This has now been corrected in both the PDF and HTML versions of the Article.

Open Access This article is licensed under a Creative Commons Attribution 4.0 International License, which permits use, sharing, adaptation, distribution and reproduction in any medium or format, as long as you give appropriate credit to the original author(s) and the source, provide a link to the Creative Commons license, and indicate if changes were made. The images or other third party material in this article are included in the article's Creative Commons license, unless indicated otherwise in a credit line to the material. If material is not included in the article's Creative Commons license and your intended use is not permitted by statutory regulation or exceeds the permitted use, you will need to obtain permission directly from the copyright holder. To view a copy of this license, visit http://creativecommons. org/licenses/by/4.0/.

(c) The Author(s) 2019

${ }^{1}$ Interdisciplinary Research Group in Infectious Diseases, Singapore-MIT Alliance for Research and Technology, Singapore, Singapore. ${ }^{2}$ Singapore Immunology Network, Agency for Science, Technology and Research, Singapore, Singapore. ${ }^{3}$ School of Biological Sciences, Nanyang Technological University, Singapore, Singapore. ${ }^{4}$ Genome Institute of Singapore, Agency for Science, Technology and Research, Singapore, Singapore. ${ }^{5}$ Department of Biological Sciences, National University of Singapore, Singapore, Singapore. ${ }^{6}$ Emerging Infectious Diseases, Duke-NUS Graduate Medical School, Singapore, Singapore. ${ }^{7}$ Department of Infectious Diseases, Singapore General Hospital, Singapore, Singapore. ${ }^{8} \mathrm{KK}$ Women's and Children's Hospital, Singapore, Singapore. ${ }^{9}$ Department of Pathogen Molecular Biology, London School of Hygiene and Tropical Medicine, London WC1E 7HT, UK. ${ }^{10}$ Koch Institute for Integrative Cancer Research and Department of Biology, Massachusetts Institute of Technology, Cambridge, MA 02139, USA. ${ }^{*}$ email: jchen@mit.edu 